\title{
CREATING A POSITIVE CLASSROOM CLIMATE TO ADDRESS DISCIPLINARY PROBLEMS IN SECONDARY SCHOOLS FOR QUALITY EDUCATION
}

TAKPI, SAMUEL ORSHIO

Dept. of Educational Foundations, Usmanu Danfodiyo University, Sokoto, Nigeria

\begin{abstract}
This paper contests the act of subjecting students to corporal punishment by the schools' administrators and teachers as a sure means of correcting disciplinary problems in the schools. It outlines effects of corporal punishment on students as; affecting their reasoning abilities, deter their social interaction and mutual understanding, hinders active participation in their academics activities etc. It also identifies some contributing factors behind prevalence of corporal punishment in schools such as; poverty, environment, temperament etc. This paper argues for; having classroom norms, making your class interesting, value of human dignity, understanding the meaning behind the behavior etc. as ingredients of positive classroom climate. It finally suggests that; positive disciplinary actions should be imbedded in teachers' training program curriculum, remuneration of teachers should be increased to reduce their level of poverty, ministries of education at all levels should be organizing capacity building workshops in the most demanding areas of education such as; disciplinary management, class control, teaching methodology and resources etc. for teachers and schools' administrators at least once in every two years.
\end{abstract}

Keywords: Creating, Positive classroom, Climate, Disciplinary problems, Secondary schools and Quality Education

\section{Introduction}

Many teachers (schools) have seen corporal punishment as a sure means of correcting students in their classes or schools. Corporal punishment is the intentional application of physical pain as a way to change a person's behavior. This may include: hitting, slapping, pinching, shaking, using objects such as a stick, forcing painful body postures and using excessive exercise drills (Greydanus, Pratt, Hofmann \& Tsegaye Spates, 1992). Corporal punishment is an ineffective method of discipline and has serious negative effect on the psychosocial, physical and mental health of students. The biblical verse that says: "spare the rod and spoil the child" (Proverbs 11: 7) does not literally mean what people perceived. Psalm, 23: 4 says: "thy rod and thy staff they comfort me" therefore the literal meaning of rod in the Bible is the code of conduct that is meant to guide, direct and instruct a person to exhibit a rightful and acceptable behavior.

Even though corporal punishment results to immediate obedience, it oftentimes does not result in improved acceptance of the school's rules. Corporal punishment does not support long-term modification in students' behavior but rather, the beaten students change their behavior at that time to avoid a future beating. Instead of simply focusing on the short term goal of stopping inappropriate behavior, school discipline should concentrate on the long term goal of helping students take responsibility for their own positive behavior (Katrina, 2011). Corporal punishment does not help a (child) student to develop into an adult with self-discipline and respect for other people, instead it distorts sound judgment and creates anti-social behaviors (Lillian, 2006). Students who are beaten are more likely to cheat, lie, be disobedient in the long-term, and also show less remorse for their misbehavior (Straus, Sugerman \& Giles-Sims, 
1997). When students feel pain instead of considering the inappropriateness of their behavior the beaten students typically focus their attention on resentment of the teacher who hurts them (Amstuts \& Mullet, 2005).

Generally, students engage in behaviors that are counterproductive to learning and contrary to accepted social practice. Sometimes students may misbehave because they feel bored, frustrated, upset, and helpless or simply mischievous while in school. In actual sense negative behaviors call for disciplinary action. So, teachers should as well view students' misbehavior as an opportunity for students to learn about morally and socially acceptable behavior. All harsh disciplinary measures adopted by authoritarian/totalitarian parents and teachers to discipline children lead to anti-social behavior, contribute to academic failure, social rejection, reduce self-esteem and create depressed mood, which in turn add to the likelihood of delinquency in adolescents (Patterson, 1982).

\section{Effects of Corporal Punishment on Students}

Arab, Waseem, Umar, Mohammad \& Quisar, (2011), listed below the following effects of corporal punishment on children;

Academic performance/career: It impedes their class participation, decreases their attendance, creates fear and hesitation among students, hinders students learning capacity, hinders students creativity, results in poor academic performance, negatively affects students' confidence, creates reluctance among students and increases dropout ratio.

Psychological effects: It causes depression, lowers self-esteem of students, causes pessimism creates inferiority among students, causes mental harassment, increases mischievous behaviors.

Personality development: It suppresses students' potentials for growth and development, students become impulsive and emotionally instable, compels students to be rebellious and uncompromising, results in social maladjustment in future, engrains the seeds of hostility and revenge to the existing system and people, creates passive aggression and harsh behavior, creates hatred for self and others in future, brings about self satisfaction, makes students rigid and violent in nature and leads to suicide in extreme cases.

The effects of corporal punishment enumerated by Global Initiative (2016), have the following consequences on the lives of the children;

Direct physical harm

Poor moral internalization and increased anti-social behavior

Increases aggression in children

Damage to the child-parent relationship

Perpetuation of violent, anti-social and criminal behavior

Causes poor mental ability

Damage to education of students

Therefore, corporal punishment has long lasting effects in the lives of students which are unacceptable in the society. These effects are as follow; 
Psychological problem: Corporal punishment distorts the development of cognitive skills in students. This thwarts the positive reasoning abilities by triggering inborn feelings like; anger, stress, fear, shame or disgust and suppress interest and enjoyment of the students that could possibly be motivated and channeled into life-long process of individual positive cognitive development. Positive classroom climate explore positive inborn feelings and re-set negative ones in students.

Sociological problem: Physical punishment deters mutual relationships like; studentstudent, student-teacher child-parent and individual-group relationship. Corporal punishment brings mistrust among students and risks their interaction with one another. It also make students view the society as the survival of the fittest i.e. authoritarian society, you can survival by the expense others.

Academic problem: Students who go through corporal punishment in the hands of their or school authorities perform poorly in the academic activities compared to their other counterparts who are free from physical punishment. It makes students lose concentration in the class, afraid of participating and hinders their learning and creativity capabilities, and most end up as dropout. It has never been in the history that people who excel in various fields of life was because of they were maltreated or punished but has been out of love and encouragement.

Health problem: Children who are spanked, hit or pushed have an increased risk of mental problems when they grow older (Rupert, 2012). Corporal punishment is associated with mental health problems during childhood and adolescence and in adult life (World Health Organization, 2009). We have also seen cases where students are injured, deformed or even died as a result of subjecting them to physical punishment.

\section{Factors contributing to administration corporal punishment in schools}

Most factors that contribute to administration of corporal punishment in schools are not the problems of the students but due to the following;

Poverty: Children who came from poor families are exposed to more corporal punishment out of parents' stress and frustration. In the same vein it assumes that teachers who are experiencing poverty are mostly found in the act of administering corporal punishment on students in classes or schools.

Temperament: Inability to manage anger is also a contributing factor to corporal punishment in schools. Some teachers who cannot control their anger do strike once they noticed any act of misbehavior in the class. In most cases these teachers do not really understand the meaning behind the action but then pass the final judgment.

Ignorance: Many people claim that they have no knowledge of the effects of corporal punishment on children. Even teachers who are supposed to be current on issues of this nature follow these people to claim lack of knowledge on this aspect of education.

Environment: People that grew up in the environment that is violent in nature look at corporal punishment as a normal way of handling misbehavior. The environment here may be family, culture or a geographical location as case may be. 
Promoting Positive Behaviors in Schools

Quality Education

Strategies for promoting positive behaviors in schools can be grouped into two: The first is to prevent misbehavior from occurring in the first place by creating a positive classroom climate. However, since misbehavior does occur, the second strategy is to develop a restorative discipline approach to managing misbehavior (Katrina, 2011). But for the purpose of this paper, it will focus on creating a positive classroom climate.

\section{Ways of creating a positive Classroom Climate}

There are two ways that teachers can take when considering students' behavior in the classroom (Eggen \& Kauchak, 2004).

The disciplinary perspective: This is the situation where a teacher assumes that as he is going to the class students will misbehave, so the only control measure is to punish students when they misbehave. This perspective is not the best for classroom control, it can only make students obey the rules when the teacher is present, but they often return to their misbehavior as soon as he is absent. Teachers are discouraged from using this approach.

The classroom management approach: This is a situation where a teacher intentionally develops strategies to create and maintain an orderly learning environment. A class that is orderly, interesting, respectful reduces students' misbehaviors and disciplinary problems are less to occur. A class where a teacher has mastery of the subject and follow his lesson sequentially has more meaning with less confusion and attracts more respect of the subject and the authority.

\section{Elements of a positive Classroom Climate}

The following elements must be contained in any Classroom Management to make it alive:

Have an organized class: Organization of any lesson is very important in the conduct and behavior of students toward that lesson (teacher). This component has to do with; preparedness of the lesson and of the teacher before going to face students. It encompasses the sequential planning of the lesson plan from simple to the complex. This also entails physical sitting arrangement of the students, position of the teacher in front of the students and words use.

Have classroom norms: A teacher wants appropriate and cooperative behavior to become the rules of the classrooms, but this can only be done when the students understand and practice the behaviors you expect of them. Each classroom needs rules that are fair, consistence, reasonable and age appropriate (Morrison, 2006). The listening abilities of students are in correspondence with their ages. For example you cannot expect a nursery pupils to have long period listening to his teacher like a primary pupil. Secondly the reason for a set rule must be well explained so that the students may take it upon themselves to implement. Lastly all classroom rules must be fair to each students regardless of their gender, tribe, religious, social status and personal (emotion) issues. When students recognized a partial judgment in 
the classroom where the group of students or a particular student is held to a different standard than others, are more likely to misbehave because of the perceived injustice and don't compromise the norms.

Have a defined classroom goal: This component looks at; having a goal oriented classroom situation that aims towards achieving a particular objective at the end of the lesson. In this regard a teacher must make the topic to be treated very clear for easy understanding, he must also use concrete teaching aids that are in themselves sound messages and self explanatory of the topic, divert and channel attention of students to your targeted goal. The communication skill of the teacher is also very crucial at this point, as a soft voice indicates acceptance, control and authority of the subject and the class.

Value of human dignity: To develop a positive classroom management the class members must be respected and cared for. When students understand their value they are less likely to misbehave. Therefore, teachers should develop a classroom environment where students feel valued, respected and cared for (Greydanus, 2010). To do this, teachers should; listen to the students' perspective and react in ways that maintain a positive relationship and encourage further discussion, praise students for their positive behaviors and encourage others to embrace likewise, call students by their names, and don't sell yourself to students on any condition be it friendship, relationship or material gains. Students who feel cared for by their teachers have better school attendance, lower misconduct, dropout rates and have more academic success (Frieler, 2010).

Make your class interesting: The classroom must be an interesting and enjoyable place for students to spend their time. Oftentimes students misbehave simply because they are bored or frustrated (Katrina, 2011). In planning the lesson the teacher should carefully make it; interesting and enjoyable for all students, relevant to students' lives, engage students in tasking activities, allow students to contribute their ideas, build on the contributed ideas to make a concrete and standard level of learning, teach emotions and ignore bad behavior, use words instead of actions. Students can engage in misbehaviors when too much or too little is expected of them in the classroom (Morrison, 2006). In the nutshell, lesson topic should consider students' level of understanding, because students get frustrated when the task is too difficult and bored when it is too simple resulting to various forms of misbehaviors in the class. Therefore, we advocate for high quality teaching that considers the students' learning ability that will drastically curtail the misbehaviors in the class and serve as the disciplinary action in schools.

Don't give for what you take: Many teachers have the knowledge of creating a positive classroom climate but because of poor remuneration of teaching profession, they are reluctant in performing their vocational duties. So going into the class, teachers should have these in minds; they are serving humanity, working for their salvation, appreciating God for what he has given them. This component condemns the idea of taking teaching job as a second alternative in totality.

Understand the meaning behind the behavior: It is possible that after all the above components mentioned students may still misbehave in the class or school. At this point the teacher is to understand why a student or a group of students behave in the way they behaved. He /she should ask the following questions: why this behavior? Who portrays such behavior? When and how? By 
answering these questions the teacher will be able to understand the meaning behind such behavior.

\section{Conclusion}

If it is constitutionally unlawful and morally wrong to hit, slap, fight, insult and even quarrel with an adult like you. Why is it allowed doing these to the little children who may exhibit a certain behavior without knowing the cause, expecting to be corrected if they are wrong but rather receive these undeserved punishments which are not acceptable even on the adults. Peace is the home of every heart, and violence in the heart is more destructive to development than physical attack.

Creating a positive classroom climate is the best disciplinary management approach teachers, schools, and ministries of education can adopt to minimize disciplinary problems in the schools. Often times, students misbehave because of frustration, boredom or they did not understand the activities in the class. Positive classroom climate help the teacher to find out the student's problem and attack the problem than attacking the student. Most often teachers went on attacking the student instead of looking for the solution to the problem. Correcting the student without solving his/her has no meaning and there is no permanent cure in it, the action will be repeated.

\section{Recommendations}

It suggests that:

Teacher Training program curriculum should include positive disciplinary actions stating how and when they should be applied and Schools should be organizing workshop for teachers to educate or remind them on how to create a positive classroom climate.

Ministries of education at all levels should be organizing capacity building workshops in the most demanding areas of education such as; disciplinary management, class control, teaching methodology and resources etc. for teachers and schools' administrators to review the achievements, challenges and action plan in every two years.

Schools and Teachers should be instructed to adopt positive classroom climate as an alternative to corporal punishment as a measure of correcting students' misbehaviors in the class rather than application of physical pain to change the behavior.

Curriculum planners should involve those who implement it, so that the practical and life classroom situation will be reflected.

States should have a department of curriculum review to see whether the planned curriculum is age wise and addressing the educational needs of the students in their various states, as the need of education may various from state to state.

Teachers' salaries should be increased to the level that they can be able to meet up with their basic needs, as help reduces temptation beating, cheating and even ignoring their profession to take other lucrative jobs because of frustration and anger. 


\section{Reference}

Amstutz, L. S. \& Mullet, J. H. (2005). "Teaching responsibility, creating caring climates": The little book of restoration discipline for school. Intercourse, PA: Good Books.

Arab, N.; Waseem, K.; Umar, D.; Mohammad, H. \& Quisar, K. (2011).” The impacts of corporal punishment on students' academic performance/career and personality development up to secondary level education in Kheyber Pakhtunkhwa Pakistan”: International journal of Business and Social Science. PP. 130-140.

Eggen, P. \& Kauchak, D. (2004). Educational psychology: Windows on classrooms. Upper Saddle River, NJ: Pearson Prentice Hall.

Frieler, J. (2010). "Corporal punishment in schools and its effect on academic success": Testimony to the U.S. Committee on education and Labor. Retrieved August 20 , 2017 from http://edlabor.house.gov/document/111/pdf/testimony/20100415JanaFrielarTe stimony,pdf

Glendcorpun, (2016). Global Initiative to End all corporal punishment of children: Working paper. UNICEF. Retrieved from www.endcorporalpunishment.org

Greydanus, D. E.; Pratt, H. D.; Greydanus S. E. III; Hofmann, A. D. \& TsegayeSpates, C. R. (1992). "Corporal punishment in schools": A position paper of the society for Adolescent Medecine, Journal of Adolescent Health, 13: 240246.

Katrina A. K. (2011). Restorative discipline as an alternative to beating in Nigerian schools: Journal of the Nigerian educational psychologists, PP. 31-37.

Lillian, H. B. (2006). "Negative effects of corporal punishment on children": Viewpoint. CYC.net. retrieved September 3, 2017 from internet.

Morrison, G. S. (2006). Fundamentals of early childhood education $\left(4^{\mathrm{ed}}\right)$. Upper Saddle River, NJ: Pearson Prentice Hall. 
Justn D. S.; Thomas J. D, \& Patterson, G. R. (1982). Coercive family process and Early-Onset Conduct Problems from Age2 to School Entry. Development and psychopathology. Eugene, OR Castalia. www.ncbi.nlm.nih.gov

Rupert, S. (2012). Spanking children can cause mental illness: Medical News Today. Retrieved from www.medicalnewstoday.com

Straus, M. A.; Sugarman, D. B. \& Giles-Sims, J. (1997). Spanking by parents and subsequent antisocial behavior of children. Archives of pediatrics and Adolescent Medecine, 151: 761-767.

World Health Organization (2009). Severe physical punishment: risk of medical health problems for poor urban children in Brazil. U.S National Library of Medicine National Institutes of Health Bulletin. Bulletin, 87: PMC 2678773. 